\title{
Immersion In Another Culture: Paradoxical Experiences Considered For Teachers And Students In University Classrooms
}

Catherine Aquino-Russell, University of New Brunswick, Moncton Campus, Canada Roger Russell, Crandall University, Canada

\begin{abstract}
We have worked, learned, and lived in Indonesia. These experiences prompted Roger's PhD dissertation entitled: Expatriate Managers' Immersion in Another Culture: A Phenomenological Study of Lived Experiences. The findings of this research uncovered eight paradoxical experiences that were lived by persons who were immersed in another culture. We have shared these paradoxes with others and have found that they, too, have experienced similar situations and feelings. We believe that these paradoxes are universal and could be viewed from the perspective of teachers in university classrooms and their students, each of whom may or may not "come from away". By taking the opportunity to illustrate these paradoxes from individuals' perspectives in this paper, understanding will ensue about what it is like to be immersed in another culture, thus transcending understanding -- to seeing the phenomenon (being immersed in another culture) in a new light. This insight will assist teachers and students from different cultures to feel understood and supported in classrooms.
\end{abstract}

Keywords: Immersion in another culture, paradoxical experiences, cultural humility

\section{INTRODUCTION}

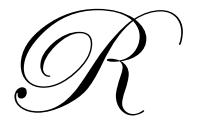

oger, our two daughters, Catrina and Allison, and I (Catherine) have lived, worked, and learned in Indonesia. We took a posting in Jakarta with the a Non-Government Organization from 2000 to 2002 which prompted us to quit our jobs in New Brunswick, Canada and sell most of our things to move away. Roger worked as a project manager developing cooperatives with the Indonesian people at the grass roots/community level in various places around Indonesia. I was working on my $\mathrm{PhD}$ out of Curtin University in Perth, Western Australia while at the same time I was very involved at the Jakarta International School, which our daughters attended. JIS, as it was called, is known as one of the best international schools in the world, with everything one could think of for resources along with teachers and students from 60 different countries around the world. It was our time in Indonesia and the experiences we had had that prompted Roger's PhD dissertation upon our return to Canada. The title of his research is: Expatriate Managers' Immersion in Another Culture: A Phenomenological Study of Lived Experiences (Russell, 2006).

Roger employed a phenomenological method for his research study, namely Giorgi's (1970, 1985; Giorgi $\&$ Giorgi, 2003) descriptive phenomenological method, to uncover the meaning of what it was like for expatriate managers to be immersed in another culture. Fifteen Canadian men and women participated in the study, which involved each of them writing a description of what it was like to be immersed in another culture. They submitted their descriptions via email. This was a great way to collect data, since Roger had returned to Canada and was studying out of Perth, Australia, while the majority of his participants were still in Indonesia (although some had moved to other countries as well as back home to Canada). 
The findings of his research uncovered eight paradoxical experiences, lived by persons who were immersed in another culture. We have shared these paradoxes with others and have found that they, too, have experienced similar situations and feelings. In fact, Roger used this as an introduction into a master's level international and intercultural management course that he was teaching at Dalhousie University in Halifax, Nova Scotia, Canada. He found that the students were very much able to relate their experiences to the paradoxes. We believe that these paradoxes are universal and could be viewed from the perspective of teachers in university classrooms and their students, each of whom may or may not "come from away".

Our intent, with this paper, is to share with you the paradoxes along with a few examples from the participants (using pseudonyms) and our own experiences. We will also share with you examples from students' viewpoints. We will discuss how we, as professors at universities with international students, need to understand the experience of living paradox and utilize various interpersonal teaching-learning strategies to enhance students' experiences, especially for those who are immersed in another culture.

\section{PARADOXES}

We have defined paradox as "seeming opposites, yet are dimensions of the same rhythm, lived all at once, with one in the foreground and one in the background" (Parse, 1998, p. 30). The paradoxes that were uncovered in this research are:

1. Understanding/Not Understanding

2. Discomfort/Comfort

3. Powerfulness/Powerlessness

4. Belonging/Not Belonging

5. Being Open to New Culture/Yet Holding on to Own Culture

6. Freedom/Restriction

7. Being Supported/Not Supported

8. Being Changed /Unchanged

In this paper, we will present each paradox from the general structural description of the research, and provide examples from participants, ourselves, and students for elaboration.

\section{Understanding/Not Understanding}

The paradox for participants of experiencing feelings of Understanding/Not Understanding is portrayed in the following component of the general structural description (which is the meaning of the lived experience according to Giorgi's method). It is:

Despite cultural training, previous experiences, and feelings of cultural knowing and understanding, being immersed in another culture inevitably surfaces potential feelings of embarrassment, anxiety, and uncertainty with not understanding (Russell, 2006, p. 259).

Research participants described how feelings of not understanding often occurred even though they possessed a sizable amount of knowledge as a result of cultural training and previous experiences. For example, Pak Jasiento, in his experiences with a wedding ceremony, described never fully understanding the cultural experiences notwithstanding significant cultural training, self-training, plus three years of experience living and working in Indonesia. Another participant, Prunes, continued to be "surprised, alarmed, elated, and frustrated by this multicultural nation" despite his 16 years of experience living and working in Indonesia. Justin Edwards credited past experiences in various developing countries and subsequent in-country cultural and language training in greatly enhancing his adjustment to the Indonesian context.

A few months after our arrival to Jakarta, I (Catherine) was a passenger when we had a car/motorcycle accident. It was a frightening experience, especially since other expatriates, in their advice to newcomers, had instructed us that "if you're ever in a car accident, tell your drivers to drive away - quickly, because they had heard 
of situations when expatriates/foreigners were pulled out of the car, beaten, and robbed. These are the thoughts that went through my mind as our car crunched over a motorcycle which was being ridden by a family of three-a manwith a helmet; a woman, and a little boy about 4 years old. I saw a large group of people surround the family, helping the woman and the boy, who was crying. I looked over at our driver, Lusino, he smiled at me, and said "sorry" and then he got out of the car. I looked out the passenger window, to see what seemed like hundreds of faces glaring at me. I wanted to get out of the car--I am a nurse--but I was frozen to my seat. I felt like a caged animal, suddenly feeling very vulnerable, worried about what might happen to me and not understanding or knowing what to do in the situation. I tried to call Roger, but our cell phone was not working properly. Then, a small-framed, smiling man, with two large loads of some sort of cookie hanging from both ends of a stick that was propped across his right shoulder, was at my car window wanting to sell me some. I was having a hard time believing this was happening. It seemed surreal. I looked at him with disbelief. He smiled broadly and pointed to his cookies, motioning that I should buy some. Unpredictability of people's behaviour left me feeling threatened and confused and not understanding where people were coming from. One thing for sure was that we learned to expect the unexpected.

One student, who had just moved to Canada, shared an experience where he had come across a mattress and couch sitting in the hallway of his apartment building. His understanding was if any furniture was located on the main floor of the building was that it was 'free to those who wanted it'. However, he found out that the owners of the furniture were just awaiting some help to bring it up in the elevator to their apartment. The owners were distraught because it appeared that someone had stolen the furniture, while the student owned up to taking mattress/couch because he thought he understood the practice of the apartment tenants, while he did not.

These experiences of understanding/not understanding are supported in the literature. For example, the literature confirmed that training, both cultural and language, is important as it serves greatly to assist an expatriate in successfully living and working in an otherwise unfamiliar cultural environment (Forster, 2000; Mendenhall et al., 2002; Suutari \& Brewster, 2001). However, at the same time, the literature reinforces the notion that there are deficiencies in training practices from the expatriates' perspective (Suutari \& Brewster). This is congruent here, where despite significant training; expatriates still do not fully understand cultural behaviours as experienced on an ongoing basis. This may be due partly to the reality that unique personal and professional challenges which expatriates experience are not well understood by others (Black \& Gregersen, 1999) and, therefore, cannot be integrated into expatriate training programs.

\section{Discomfort/Comfort}

When being immersed in another culture, one feels discomfort with the trial and error processes that enhance one's learning and avoidance of cultural errors. Adjustment and comfort occur amidst inescapable feelings of alienation, irritability, and unhappiness. These feelings of discomfort are countered somewhat by cultural comfort and knowledge of 'going home' (Russell, 2006, p. 263).

The research participants described the process of trial and error as essential in learning how to participate appropriately in the new cultural environment. One participant, Thomas Austin, described feeling uncomfortable with the necessity of learning as one goes, and that there was no rule book to use as a guide. Batik utilized the term "lessons learned", which is common 'lingo' in non-government organization (NGO) circles, to describe how she would build on her knowledge through actual experiences while at the same time she would seek cultural knowledge from cultural mentors in regards to getting comfortable in new situations. Batman described how his learning "on the fly" led to a discomforting situation when participating in an inappropriate behaviour according to local religious customs. Being repatriated to Canada is a comforting thought that was described by Made, Prunes and Pak Jasiento. Prunes specifically described his discomfort at being laughed at (when he was burned by the hot 'sambal') and not being able to be himself (when he was unable to speak the language well enough to make jokes), while at the same time he took some comfort in his thoughts of home and his pending "escape" which would happen "in eight weeks".

I (Roger) had a meeting set up with two key Partners in the project that I was managing. I had set up a meeting to see what had been accomplished to date on the project. I chose a breakfast buffet meeting, where we could eat and talk about business. The Partners initially were not interested in talking about business. They wanted 
to socialize and enjoy the company and the food. I felt awkward in that the goals that I had set for the meeting did not get done. My agenda was different than theirs. It was several months later that I found out that the Partners experienced discomfort that I did not take the time. I found this a dramatic learning opportunity and certainly altered my approach later to 'go with the flow' of those with whom I was working.

Two western European students in my (Roger) class in Canada were concerned about their language proficiency. They experienced discomfort with their abilities to write papers in English-a reality for those who had English as a second language. They spoke of how comfortable it was for them to write in their own language, and sometimes how they longed to go home. I spent much time mentoring them in writing papers, which, I think, made a difference in their experience and helped them to feel more comfortable. Overall, these examples illuminate the reality that while being immersed, learning about the culture by doing, and experiencing through what is commonly known as a 'trial and error' process happens. While learning in this manner, people frequently described being upset and uncomfortable. The notion of returning home was a comforting thought.

These findings are supported in the literature. Indeed, it is well documented that expatriates typically experience difficulties when moving across cultures (Jun et al., 2001). For example, according to Osland (1995), "many expatriates have to plumb the depths of their inner resources, first to survive the differences and changes, then to be effective" (p. 3). A great deal of the extant literature relates to the challenges of the cultural adjustment process including the phenomenon known as culture shock (Oberg, 1960). There is no doubt that feelings of discomfort/comfort are common during this adjustment process which may be a never-ending process.

As reinforced in the literature, performing or behaving appropriately while being immersed in another culture can be described as a trial and error process. Zimmerman et al. ( 2003) utilized the term "exploration" in describing how the expatriates gradually modify their inclinations and behaviours based on their experiences in the foreign cultural environment (p.48). The literature supports the fact that cultural errors in Indonesia by Westerners are common. Indeed, most often, adjustment is about "the gradual development of familiarity, comfort, and proficiency regarding expected behavior and the values and assumptions inherent in the new culture" (Black \& Mendenhall, 1990, p.118). This progression of reducing uncertainty, minimizing inappropriate behaviors and other errors or setbacks takes time. Also in relation to this paradox, the comforting thoughts of going home (or repatriation) are also considered a lived experience of expatriates. This finding is supported in the literature by the very nature of overseas assignments which normally involves expatriates having future plans that include returning to their own country (De Cieri et al., 1991).

\section{Powerfulness/Powerlessness}

Foreigner status and feelings of powerfulness are present when being immersed in another culture; however, observable differences give rise to feelings of powerlessness, vulnerability, self-consciousness, and being judged by others (Russell, 2006, p. 268).

Several research participants described their elevated status as foreigners and the feelings of powerfulness or powerlessness it entailed. Pak Jasiento described being invited to numerous weddings for people they barely knew and in some cases invitations from people they did not know at all, simply because they were foreigners. Although Pak Jasiento just wanted to blend into the crowd at a wedding he attended, he described being seated in a prime location for all attendees to see. This served to enhance his hosts' social status but left Pak Jasiento with feelings of being used, self-conscious, and vulnerable. Prunes, although in a position of power, felt powerlessness amid the local cultural milieu and in dealing with what appeared to be a serious health issue of an Indonesian coworker, and so he reluctantly agreed to engage in the services of a 'dukun' (traditional healer). On the other hand, when Martin Wyatt was faced with a serious health issue of a fellow Canadian he felt his status as foreigner led to increased powerfulness which was not typical for Indonesians of a similar age and experience. In Indonesia, Canadians are generally a visible minority which provides for instant identification that one is a foreigner. Kate Phelan described her self-consciousness at being the only foreign face among a large group of Indonesians during an annual religious pilgrimage. While Batman described his feelings of being vulnerable to higher pricing of goods/services simply because of his status as a Westerner and knowing there is little that can be done regarding the reality of 'observable differences'. 
For me (Catherine), referring back to the car accident example, I spoke with the driver of the motorcycle after the accident. I realized the 'power' I had when he begged me 'not to punish my driver'... This is not even something that I had thought of, but I have heard that many expatriates would actually fire their drivers if there had been an accident. So amidst feeling powerless in the accident, I also recognized the power I had as a foreigner-which I did not want to use.

Students from other countries have described more 'powerless' experiences, than powerful ones, i.e., being unsure of rituals or rules for deadlines as well as certainly feeling 'different' and standing out amidst others.

Overall, these findings point to the fact that the expatriates as foreigners, readily identified through 'observable differences', brought power and status, but also feelings of powerlessness in certain situations. Feelings of vulnerability and self-consciousness were experienced frequently as well.

The findings are supported in the literature by Osland's (2000) research. She described a phenomenon called a "marginality paradox" (p. 233) where expatriates generally think well of the local persons while simultaneously being very cautious so not to be taken advantage of by these same hosts. In reference to powerfulness, Osland (2000) identified a "social acuity paradox" (p. 233) that has the expatriate possessing a great deal of power, yet not exercising this power in order to obtain full participation and mutual assistance from host nationals.

\section{Belonging/Not Belonging}

Expatriates have dispiriting feelings of belonging, yet never really belonging, when being immersed in another culture. The feelings arise amidst the reality and contentment of special treatment by hosts and home when - sought after for sharing one's opinion, utilized as a sounding board, and mentored yet knowing and feeling one will not ever truly belong (Russell, 2006, p. 272).

The research participants described experiences in which they had feelings of belonging, yet realized they were always going to be outsiders. Thus, the potential for belonging in a substantial way to the Indonesian cultural environment was limited or non-existent. This reality was illuminated by Made who stated, "While I have always felt comfortable with Indonesians around me and they have certainly made me feel at home, I cannot say that I have ever felt Indonesian". Made was able_to experience momentary feelings of belonging and being perceived as Indonesian because he had mastered the Indonesian accent, but only while speaking on the telephone and not being seen. Imron pointedly wrote "I will always be an outsider" after believing he had understood all of the words during a discussion but somehow he nonetheless completely missed the message.

We (Roger and Catherine) too felt very welcomed by the Indonesians but there were times when we were referred to as 'foreigners' which brought it home that we did not really belong.

Students at the Jakarta International School had a tendency to 'hang around' with others who came from the same country (i.e. South Korea, America, etc.) as they did, thus experiencing that sense of belonging to groups of students from their own culture, while at the same time feeling like outsiders when amidst other students. Observable differences related to their experiences of belonging/not belonging.

Overall, these findings point to the fact that people experience feelings of belonging $\mathrm{n}$ the local cultural environment; however, these special feelings tended to be intermittent and superficial. Although participants wrote frequently of receiving special treatment, they also accepted that they will always be considered as outsiders in the eyes of the local people.

\section{Being Open to New Culture/Yet Holding on to Own Culture}

When being immersed in another culture one experiences feelings of being open to new cultural experiences; yet one holds on to one's own national culture through comparisons while at work and in non-work situations (Russell, 2006, p. 276). 
All participants' descriptions were interpreted as being open to the new (Indonesian) culture, yet they described everyday experiences in which they compared or judged the Indonesian culture against the Canadian culture, recounting similarities and differences. Further, there were descriptions that depicted the Canadian expatriates promptly reverting to behavioural patterns that are typical within the Canadian culture when faced with highly stressful situations. For example, one participant, Thomas Austin, wrote about "fiercely" clinging to his own "cultural backpack". Certainly, Thomas Austin was open to fully experiencing the new culture but even after three years in Indonesia he described feeling "held back" by frequent feelings of bewilderment and confusion about the host culture. Other participants consistently described their openness to the new culture, yet often looked to their home culture as a standard or benchmark in making sense of particular aspects of the host culture. For example, Batman reflected on the attitudes of the health care providers in determining that they were very comparable to the Canadian situation. Similarly, Batik, when invited to an Indonesian wedding ceremony that was to take place in its entirety between 5 p.m. and 7 p.m., instantly recalled the numerous Canadian weddings which involved a much larger timeframe.

We were open to the new culture, yet we enjoyed our own culture while we lived in Jakarta. We chose to hire a 'house helper' for the weekdays, rather than hiring a live in 'maid' (which our home was set up to accommodate). We wanted have weekends to be a 'Canadian Family', to sit, chat, watch videos, play games, etc. without someone in the house picking up after us.

For one Indonesian student, she described being open to experiencing the new culture, but she was worried about the cold weather in Canada and if she would survive it. She also described having challenges finding food that was congruent with her religion. She was left on her own for the weekend, while Canadians went home from work to attend to their own agendas. She said that this behaviour differed in the Indonesian culture where the Indonesians would be available $24 / 7$ to entertain visitors.

Feelings of being open to a new culture, yet at the same time holding on to one's own culture is a primary component of the findings. Aspects of this are supported in the existing academic literature. For example, although one may be open to a new culture, one's own culture has an all-encompassing power and grasp because "a person's perceptions, attitudes, motivations, values, learning experiences and personality are all, to a very large extent, shaped by culture" (Forster, 2000, p. 64). Of particular interest is Forster's contention that, usually, we do not think consciously about our culture, nor are we even aware of it (Oberg, 1960) until we are in circumstances such as living, working, and learning in a different culture. Congruency with the extant literature is seen in relation to participants' hasty reversion to their familiar Canadian culture in cases of serious health crises. Even in cases of much less urgency, it is only normal to gravitate to the familiar. One might rationalize that this is why many Canadians and others who are overseas often seek out other members of their own culture to socialize with or why they find themselves frequently eating lunch at familiar fast food restaurants (Black \& Gregersen, 1999).

\section{Freedom/Restriction}

When being immersed in another culture one's feelings of freedom are restricted through lack of comprehension of unwritten, unpredictable, contradictory, and mystical cultural practices of hosts. What emerges is a constant cautiousness for one's own personal security (Russell, 2006, p. 281).

The participants expressed thoughts related to situations of experiencing paradoxical feelings of freedom/restriction. For example, Archer's experience of being immersed in another culture meant being fully occupied at a time when his life was restricted to activities involving the adjustment to the new working environment and learning the Indonesian language. In fact, it was so restricting for him that he described the situation as leaving "the monastery" when he finally, after some time in Indonesia, was able to get his freedom upon renting his own house. Archer described this regained independence (or freedom) as "getting his life back" meaning it was more in line with how it would have been had he been living back home in Canada. In a similar vein of thought, Prunes described his immersion in another culture as analogous to a zoo animal where freedom/restriction is a way of life for the animals. He also described feeling like a "space alien" thereby, as with zoo animals, was never free from inquisitive gawking and invasion of privacy. Prunes even described his anticipated end of the assignment departure date as when he would make his "escape" (from the restriction) by returning home to Canada. 
We, too experienced feeling like arctic wolves in the zoo each evening as we walked around our guarded, gated, and fenced in villa, which was inhabited by expatriates from around the world. We enjoyed the warmth of the 32 degree Celsius weather gazing up at the palm trees and around at lush green gardens, saying to ourselves-"we don't ever want to forget this feeling" while at the same time looking through the fencing to a group of young boys playing soccer barefooted in the field adjacent to our villa. They would stop, smile, and watch us as we walked by. We would comment about the interesting and paradoxical feelings of being free, yet feeling restricted saying: who is free here? It didn't seem like it was us. And then asking: Who is on display here? It was us.

One student from Africa described freedom to do whatever he wants to do here in Canada, and was only restricted because of his financial status as a student. Whereas a European student said she could blend in with Canadians - free to come and go as she pleases.

The extant literature supports the paradoxical concept of freedom/restriction. For example, Osland (2000) referred to being freed from many of one's own cultural rules, yet at the same time being restricted by certain host country cultural norms, which must be conformed with if one is to function well in the foreign environment. Osland labeled this expatriate experience a "mediation paradox" (p. 233).

\section{Being Supported/Not Supported}

The deficiency of home country organizational assistance fuels ones' feelings of disappointment and feelings of not being supported amidst the generosity, caring, and community support from one's cultural guides and family in the new culture (Russell, 2006, p. 285).

The participants described various forms of support provided by local persons as helpful and meaningful experiences when being immersed in the Indonesian culture. For example, Archer described appreciating being groomed by a local cultural mentor at the NGO where he was employed. Further, Batik wrote of having received generous cultural guidance from local friends who wanted to ensure she was properly dressed for an important cultural activity. She described the process of tailor-made clothes as significantly different when compared with simply buying clothing off the rack as is typical in Canada. Luke Gerard described his experience of being supported and protected by children in the community when they followed him around in his day-to-day activities. Additionally, Thomas Austin was the recipient of local generosity and caring actions from the hospitable Indonesian culture as guided by hosts' desires to make him feel supported, while Tristan Philips felt extremely unsupported by the Canadian organization that he worked for.

We experienced and survived a significant flood when we lived in Jakarta. The Indonesians supported us through this traumatic event by providing us with essentials because we were evacuated from our home with nothing more than a change of clothes, while members of our employing organization did not provide any words of encouragement or indication of understanding or support of what we were going through. We felt disconnected and unsupported by persons in the organization who were overseas.

A student from a male dominated culture experienced feelings of support/not support when he was not invited to the Christmas party with 12 female students. He described feeling not supported by his classmates, while being supported by his professors.

Overall, a significant amount of support, in the form of caring and mentorship, from various types of local hosts and communities occurred while at the same time, the level of support from home country organizations was described as disappointing despite promises of support. In the extant literature, for example, Hutching's (2002) work on expatriates indicated a scarcity of in-post support by the employing companies. Other researchers agreed that most companies do not pay sufficient attention to aspects of expatriation including in-post support (Ashamalla, 1998; Ferraro, 2002; Hutchings, 2005; Varma, 2003). In addition, the in-post support should be ongoing throughout the overseas assignment (Edkins ,1995; Jassawalla et al., 2004; Shaffer et al., 1999). The value of in-post support that is ongoing is essential but described it primarily as stemming from the generosity and caring of the local cultural community. There is little indication of ongoing in-post support extended to expatriates by the home organization. 


\section{Being Changed /Unchanged}

One's personal changes may not be recognized by others who perceive one as being unchanged; yet one's rewarding transformation of living and working while being immersed in another culture is cherished, shared with others, and memorable (Russell, 2006, p.289).

The participants described uniquely rich and memorable experiences where they gained cultural knowledge and thus experienced feelings of being changed in meaningful ways. It is interesting that Justin Edwards mentioned many negative aspects of living and working in Indonesia but still described himself as "lucky". Similarly, Luke Gerard wrote of his growth and the personal changes he experienced from living in a village where no one spoke English nor had they ever seen someone like him, except on TV. Luke Gerard's pride in sharing his story was evident when he described his rewarding transformation resulting from being so completely immersed in the Indonesian culture and surviving it! Another participant, Made, implied a sense of personal transformation whereby he had internalized the Indonesian culture leaving him changed, yet he was going to return to Canada where he may still be viewed by others as being unchanged.

When we left Canada, I (Roger), worked as a Credit Manager and after repatriation, I was viewed the same by others, however, in those two short years, I believe that I experienced 20 years of experiences changing me and our family at so many levels. The most significant changes were our appreciation for other cultures (Indonesian, friends from Japan, Australia), how we broadened our minds, the life-death experiences with accident and flood, and so many more. These experiences are forever etched in our minds.

A student from Germany stated that the experience of living here in Canada for a semester left her changed. Her English had improved significantly, she made new friends, yet, when returning home, her peers treated her as she had never left.

Overall, these findings reveal significant feelings of being Unchanged/Changed amidst treasured and memorable experiences while being immersed in another culture. There is a strong desire to remember personal experiences in order to share them with important others back home. In the extant literature, for example, most expatriates reminisce fondly about the cherished and memorable experiences of their life overseas (Richards, 1996). Also, expatriates tend to be proud of their accomplishments. For example, Osland's (2000) research findings describe the expatriates' "pride in succeeding at difficult work assignments, making it 'on their own', feeling 'special', and taking pride in their ability to acculturate and adapt to change" (p. 228).

We are very content that we had the opportunity to live, learn, and work in Indonesia. We would not want to have done it any other way. We gained so much and appreciate the Indonesian people and their way of life. It was a time in our lives filled with multiple paradoxical experiences. We believe that these experiences help us to be better professors in seeking to understand our students' experiences and altering our own behaviours to meet their needs, being ever-mindful of the perceived power imbalances between professor and students.

\section{CONCLUSIONS}

A term that is being shared around university organizations, especially in New Brunswick is "cultural humility"... where each of us must be open to other cultures and not assumes or generalize for each person is unique (Tervalon, \& Murray-Garcia, 1998; Juarez, Marvel, Brezinski, Glazner, Towbin, \& Lawton, 2006). Cultural humility is defined as:

a process that requires humility as individuals continually engage in self-reflection and self-critique as lifelong learners and reflective practitioners, it requires humility in how [we] bring into check the power imbalances that exist in the dynamics of ... communication by using [person]-focused interviewing and care, and it is a process that requires humility to develop and maintain mutually respectful and dynamic partnerships with communities (Tervalon, \& Murray-Garcia, 1998, p. 118). 

classrooms.

This is something for University professors to reflect on when involving international students in their

Strategies to consider in classrooms are suggested:

- $\quad$ Being open to the paradoxes of being immersed in another culture

- $\quad$ Asking persons to share their experiences

- $\quad$ Reflecting on your own experiences

- $\quad$ Role-modeling ways to be with others that demonstrates cultural humility

We hope that this paper has allowed you, the reader, to transcend your understanding -- to seeing the phenomenon of being immersed in another culture in a new light. We believe that this insight will assist both teachers and students from different cultures to feel understood and supported in classrooms.

\section{AUTHOR INFORMATION}

Dr. Catherine Aquino-Russell, RN, MN, PhD completed a Bachelor of Nursing Science, Lakehead University, Thunder Bay, Ontario; a Masters in Nursing, University of Manitoba, Winnipeg; a Diploma in University Teaching, University of New Brunswick, Fredericton, Canada; and a PhD in Nursing, Curtin University, Perth, Western Australia. She has held numerous education, leadership, volunteer, and administration positions in hospitals and universities in Canada and Indonesia. At present, she holds the position of Associate Professor at the Faculty of Nursing, University of New Brunswick, Moncton Campus, in Moncton, New Brunswick, Canada.

Dr. Roger Russell, BSc (Agr), MBA, PhD holds a Science degree (Agricultural Economics), University of Guelph, Guelph, Ontario; a Master of Business Administration (Management), Saint Mary's University, Halifax, Nova Scotia, a Diploma in University Teaching, University of New Brunswick, Fredericton, New Brunswick, Canada; and a $\mathrm{PhD}$ in Business (International Management), Curtin University, Perth, Western Australia. Roger has been employed in several industries (agricultural, foodservice, banking, international development, and post secondary education) while working in five Canadian provinces and three countries (Canada, Indonesia, and Haiti). Currently, Roger is a professor, researcher, and administrator (Director of Professional Studies Division) at Crandall University, in Moncton, New Brunswick Canada.

\section{REFERENCES}

1. Ashamalla, M. H. (1998). International human resource management practices: The challenge of expatriation. Competiveness Review, 8(2), 54-65.

2. Black, J. S., \& Gregersen, H. B. (1999). The right way to manage expats. Harvard Business Review, 77(2), 52-60.

3. Black, J. S., \& Mendenhall, M. E. (1990). Cross-cultural training effectiveness: A review and a theoretical framework for future research. Academy of Management Review, 15(1), 113-136.

4. De Cieri, H., Dowling, P. J., \& Taylor, K. F. (1991). The psychological impact of expatriate relocation on partners. The International Journal of Human Resource Management, 2(3), 377-414.

5. $\quad$ Edkins, M. (1995). Making the move from west to east. People Management, 1(13), 34-37.

6. Ferraro, G. P. (2002). The cultural dimension of international business (4th ed.). Upper Saddle River, NJ: Prentice-Hall.

7. Forster, N. (2000). Expatriates and the impact of cross-cultural training. Human Resource Management Journal, 10(3), 63-78.

8. $\quad$ Giorgi, A. (1970). Psychology as a human science. A phenomenologically based approach. New York: Harper \& Row.

9. Giorgi, A. (1985). Phenomenology and psychological research. Pittsburgh, PA: Duquesne University Press.

10. Giorgi, A. P., \& Giorgi, B. M. (2003). The descriptive phenomenological psychological method. In P. M. Camic, J. E. Rhodes \& L. Yardley (Eds.), Qualitative research in psychology: Expanding perspectives in methodology and design. Washington, DC: American Psychological Association. 
11. Hutchings, K. (2002). Improving selection processes but providing marginal support: A review of crosscultural difficulties for expatriates in Australian organizations in China. Cross Cultural Management, 9(3), 32-58.

12. Hutchings, K. (2005). Koalas in the land of the pandas: Reviewing Australian expatriates' China preparation. International Journal of Human Resource Management, 16(4), 553-566.

13. Jassawalla, A., Connelly, T., \& Slojkowski, L. (2004). Issues of effective repatriation: A model and managerial implications. A.A.M. Advanced Management Journal, 6 (2), 38-46.

14. Juarez, J. A., Marvel, K., Brezinski, K. L., Glazner, C., Towbin, M. M., \& Lawton, S. (2006). Bridging the gap: A curriculum to teach residents cultural humility, Family Medicine, 38(2), 97-102.

15. Jun, S., Gentry, J. W., \& Hyun, Y. J. (2001). Cultural adaptation of business expatriates in the host marketplace. Journal of International Business Studies, 3 (2), 369-377.

16. Mendenhall, M. E., Kuhlmann, T. M., Stahl, G. K., \& Osland, J. S. (2002). Employee development and expatriate assignments. In M. J. Gannon \& K. L. Newman (Eds.), The blackwell handbook of cross-cultural management. Oxford, UK: Blackwell Publishers Inc.

17. Oberg, K. (1960). Cultural shock: Adjustment to new cultural environments. Practical Anthropology, 7 , $177-182$.

18. Osland, J. S. (1995). The adventure of working abroad: Hero tales from the global frontier. San Francisco, CA: Jossey-Bass Publishers.

19. Osland, J. S. (2000). The journey inward: Expatriate hero tales and paradoxes. Human Resource Management, 39(2,3), 227-238.

20. Parse, R. R. (1998). The human becoming school of thought. A perspective for nursing and other health care professionals. London: Sage Publications.

21. Richards, D. (1996). Strangers in a strange land: Expatriate paranoia and the dynamics of exclusion. The International Journal of Human Resource Management, 7(2), 553-571.

22. Russell, R. (2006). Expatriate Managers' Immersion in Another Culture: A Phenomenological Study of Lived Experiences. PhD dissertation: Curtin University of Technology, Perth, Australia.

23. Shaffer, M. A., Harrison, D. A., \& Gilley, K. M. (1999). Dimensions, determinants, and differences in the expatriate adjustment process. Journal of international Business Studies, 30(3), 557-582.

24. Suutari, V., \& Brewster, C. (2001). Expatriate management practices and perceived relevance. Personnel Review, 30(5/66), 554-577.

25. Tervalon, M., \& Murray-Garcia, J. (1998). Cultural humility versus cultural competence: A critical distinction in defining physician training outcomes in multicultural education. Journal of Health Care for the Poor and Underserved, 9(2), 117-125.

26. Varma, A. (2003). Stan Lomax. Best practices for managers and expatriates: A guide on selection, hiring, and compensation. Human Resource Management, 42(2), 195-196.

27. Zimmerman, A., Holman, D., \& Sparrow, P. (2003). Unravelling adjustment mechanisms: Adjustment of German expatriates to intercultural interactions, work, and living conditions in the People's Republic of China. International Journal of Cross Cultural Management, 3(1), 46-65. 